\title{
Differential regulation of glomerular gelatinase B (MMP-9) and tissue inhibitor of metalloproteinase-1 (TIMP-1) in obese Zucker rats
}

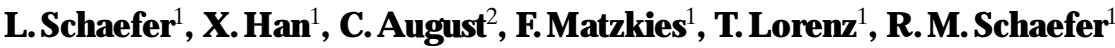 \\ ${ }^{1}$ Department of Internal Medicine University of Muenster, Muenster, Germany \\ ${ }^{2}$ Department of Pathology, University of Muenster, Muenster, Germany
}

Summary The obese Zucker rat represents a model of obesity combined with insulin resistance and hyperlipidaemia, which over a period of several months develops spontaneous glomerulosclerosis. The present study addressed the question as to whether glomerular sclerosis was associated with alterations in the degradation of matrix components. In the early phase (up to 6 months) glomeruli from obese rats displayed increased total collagen content $(+64 \%)$ and decreased gelatinolytic activity $(-34 \%)$ as compared to lean control animals. This decline in glomerular gelatinolytic activity was due to a reduction in gelatinase B [matrix metalloproteinase (MMP)-9]. Glomerular MMP-9 mRNA was reduced 4.6 \pm 0.6 -fold $(n=3 ; p<0.05)$, MMP-9 protein was not detectable by Western blotting and MMP-9 activity was considerably suppressed in gelatin zymograms. MMP-2, in terms of mRNA expression and activity, was unchanged. Tissue inhibitor of metalloproteinases (TIMP)-1 mRNA expression, TIMP-1 protein (immunohistochemistry) and TIMP-1 activity (reverse zymography) were enhanced in glomeruli from obese rats, while TIMP-2 mRNA remained unchanged. Moreover, mRNA for the $\alpha_{1}$ IV collagen chain was $2.1 \pm 0.8$-fold higher in glomeruli isolated from obese animals $(\mathrm{n}=3 ; \mathrm{p}<0.05)$. These findings indicate that matrix expansion in glomeruli from obese Zucker rats is due to both enhanced synthesis of matrix components as well as reduced degradation by matrix metalloproteinases. Apparently the latter effect is based on a reduction in MMP-9 and up-regulation of its inhibitor TIMP-1. [Diabetologia (1997) 40: 1035-1043]

Keywords Glomerulosclerosis, matrix metalloproteinase, tissue inhibitor of metalloproteinases, obese Zucker rat.
Received: 16 January 1997 and in final revised form: 28 April, 1997

Corresponding author: Dr. L. Schaefer, Med. Univ-Poliklinik, Albert-Schweitzer-Str.33, 48129 Muenster, Germany

A bbreviations: MMP, Matrix metalloproteinase; TIMP-1, -2: tissue inhibitor of metalloproteinases-1, -2; TPA, 12-O-tetradecanoyl-phorbol-13-acetate; TRE, TPA-responsive element; TNF, tumour necrosis factor; IL-1, interleukin-1; TGF- $\beta 1$, transforming growth factor- $\beta 1$; GAPDH, glyceraldehyde 3phosphate dehydrogenase; APAAP, alkaline phosphataseanti-alkaline phosphatase; PMSF, phenylmethyl-sulphonylfluoride; PAS, periodic acid-Schiff; PBSTB, phosphate buffered saline containing $0.05 \%$ Tween 20 and $1 \%$ bovine serum albumin; PBST, phosphate buffered saline containing $0.1 \%$ Tween 20.
The obese Zucker rat is an autosomal recessive model of obesity and hyperlipidaemia with many similarities to human non-insulin-dependent diabetes mellitus (NIDDM) [1-3]. These metabolic abnormalities precede the development of albuminuria and mesangial matrix expansion followed by segmental glomerulosclerosis $[4,5]$. Accumulation of matrix components within the mesangium has been demonstrated for collagen IV, fibronectin, laminin and proteoglycans [6-8].

The turnover of extracellular matrix is dependent on a balance between its synthesis and degradation, and consequently enhanced matrix deposition may be either due to increased synthesis and/or reduced activity of proteinases responsible for the remodelling of the matrix components. Several lines of evidence suggest the involvement of metalloproteinases 
(MMPs) in matrix turnover, including the glomerular extracellular matrix [9-13]. The gene family of MMPs includes the collagenases, gelatinases and stromelysins, which are $\mathrm{Zn}$-dependent endopeptidases with the combined ability to degrade all the components of extracellular matrix at physiological $\mathrm{pH}$ [14-16]. These enzymes are specifically inhibited by tissue inhibitors of metalloproteinases (TIMPs), of which TIMP-1, TIMP-2, TIMP-3 and TIMP-4 have been described [17-21].

Reduced activities of glomerular proteinases measured at neutral $\mathrm{pH}$ against azocasein [22] and fibronectin [7] as substrates have been reported previously in the obese Zucker rat. Moreover, preliminary data from our laboratory confirmed that the reduction in neutral glomerular proteolytic activities in these rats was due to a decline in gelatinolytic enzymes, suggesting a potential role for MMPs in the evolution of glomerulosclerosis in this model of renal disease [23].

However, up to now the involvement of specific glomerular MMPs has not been addressed. Among these enzymes the gelatinase subgroup, which comprises the $72 \mathrm{kDa}$ gelatinase A (MMP-2) and the $95 \mathrm{kDa}$ gelatinase B (MMP-9), are particularly efficient in degrading collagen IV, the major structural component of the mesangial matrix and glomerular basement membrane [13]. Therefore, the present study has been conducted to investigate potential alterations of glomerular MMP-2 and MMP-9 as well as their inhibitors (TIMPs) in the obese Zucker rat at an early stage of glomerulosclerosis.

\section{Materials and methods}

A nimals. We used 24-week-old male obese Zucker rats $(n=9)$ and age-matched lean littermates $(n=9)$ supplied by Savo-Ivanovas, Kisslegg, Germany throughout the study. The animals had free acess to water and standard laboratory rat chow (Altromin, Lippe, Germany). All animal experiments were conducted in accord with the NIH Guide for the Care and Use of Laboratory Animals.

I solation of glomeruli. Animals (obese: $n=9$; lean: $n=9$ ) were anaesthetized with hexobarbital $(150 \mathrm{mg} / \mathrm{kg})$, the kidneys were removed and glomeruli (from each individual animal) isolated according to the method of Spiro [24]. In brief, the renal cortex was minced, resuspended in ice-cold $154 \mathrm{mmol} / \mathrm{l} \mathrm{NaCl}$ and passed through a stainless-steel sieve $(250-\mu \mathrm{m}$ pore size, Linker, Kassel, Germany). The sieved material was suspended in icecold $154 \mathrm{mmol} / \mathrm{l} \mathrm{NaCl}$ and poured over a $50-\mu \mathrm{m}$ nylon sieve (Schweizerische Seidengazefabrik, Zurich, Switzerland), thereby allowing cell debris and small fragments to pass through, while retaining glomeruli and tubules. Separation of tubules from glomeruli was achieved by passage on a $150-\mu \mathrm{m}$ nylon sieve. Glomeruli were collected after passage through the sieve. Purity, controlled by light microscopy, was $95 \%$. Glomeruli from each kidney preparation were counted three times in a Fuchs-Rosenthal chamber. Isolated glomeruli were disrupted by sonication (3 bursts, $2 \mathrm{~s}$ each; Labosonic, B. Braun, Melsungen, Germany) at $4{ }^{\circ} \mathrm{C}$ prior to the determination of enzyme activities.
Gelatinolytic activity. Gelatinolytic enzyme activities were measured fluorometrically in glomeruli from each individual animal (obese: $n=9$; lean: $n=9$ ) as we described previously [25]. Denatured rat tail collagen type-1 (gelatin) was used as substrate. Latent enzyme was activated by preincubation with $0.5 \mathrm{mmol} / \mathrm{l}$ of oxidized glutathione. The activity of gelatinase was determined in the presence of $4 \mathrm{mmol} / \mathrm{l}$ phenylmethylsulphonylfluoride (PMSF) for inhibition of serine proteinases. After $18 \mathrm{~h}$ of incubation at $25^{\circ} \mathrm{C}$, the digested fragments were labelled with $2 \%$ fluorescamine. Fluorescence was measured by excitation at $390 \mathrm{~nm}$ and emission at $475 \mathrm{~nm}$. The assay was quantified by determining a calibration curve relating the fluorescence emission reading to an equivalent concentration of H-Leu-Leu-OH (Bachem, Heidelberg, Germany). One unit was defined at $1.0 \mathrm{nmol} / \mathrm{l}$ amino groups cleaved from the gelatin molecule per minute.

Zymograms. Gelatin-degrading activity was assayed on nonreducing SDS/10 \% -polyacrylamide gels according to Laemmli [26] incorporating $1 \mathrm{mg}$ of gelatin/ml. Gels were loaded with equal numbers of glomeruli, because in the obese Zucker rat the number of glomeruli is constant, while there is a considerable rise in glomerular protein content due to matrix accumulation. Therefore, gelatinolytic activity was normalized by the number of glomeruli. Electrophoresis was performed at $4{ }^{\circ} \mathrm{C}$ and $20 \mathrm{~mA} / \mathrm{gel}$. Thereafter, gels were washed for $1 \mathrm{~h}$ at room temperature in $2.5 \% \mathrm{v} / \mathrm{v}$ Triton $\mathrm{X}-100$ with two changes and then incubated overnight at $37^{\circ} \mathrm{C}$ in TCB buffer: $50 \mathrm{mmol} / \mathrm{l}$ Tris-HC1, $0.1 \mathrm{mmol} / 1 \mathrm{NaCl}, 10 \mathrm{mmol} / \mathrm{l} \mathrm{CaCl}_{2}, 4 \mathrm{mmol} / \mathrm{l} \mathrm{PMSF}$, $0.05 \% \mathrm{Brij} / \mathrm{pH} \mathrm{7.6}$, in the presence or absence of $20 \mathrm{mmol} / \mathrm{l}$ EDTA. Staining was achieved with Coomassie Blue R $0.25 \%$ dissolved in $40 \%$ methanol and $10 \%$ acetic acid. For destaining a mixture of $40 \%$ methanol and $10 \%$ acetic acid was used. A high-molecular mixture of protein (205-29 kDa) (Sigma, Munich, Germany) and purified human MMP-2 and MMP-9 (Anawa, Zurich, Switzerland) were used as molecular standards.

MMP-inhibitory activity was assayed in $11 \%$ poly-acrylamide gels including $0.5 \mathrm{mg}$ gelatin $/ \mathrm{ml}$. Electrophoresis was followed by incubating gels for $40 \mathrm{~min}$ at $37^{\circ} \mathrm{C}$ in a preparation of active rabbit skin gelatinase $(7 \mathrm{U} / \mathrm{ml})$ (kindly provided by Dr. G. Murphy, Cambridge, UK) before incubation overnight in TCB buffer at $25^{\circ} \mathrm{C}$. Staining and destaining were performed as described above. As a positive control purified human TIMP-1 (a gift from Dr. G. Murphy) was used.

Western blot analysis of MMP-9. Prior to electrophoresis, glomerular homogenates containing equal numbers of glomeruli were applied to a gelatin-Sepharose column ( $1 \mathrm{ml})$ equili-

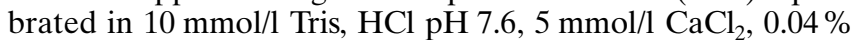
Brij 35 (v/v) and washed with the same buffer. Bound material was eluted with equal volume of the same buffer plus $10 \%$ dimethyl sulphoxide. The gelatin-binding fraction was further concentrated 50-fold using Microcon 10 concentrators (Amicon, Beverly, Mass., USA). Samples (20 $\mu \mathrm{l})$ and standard purified human MMPs (100 ng) were subjected to electrophoresis on $10 \%(\mathrm{w} / \mathrm{v})$ gels under reducing conditions. Proteins were transferred electrophoretically at $100 \mathrm{~V}$ for $1 \mathrm{~h}$ to nitrocellulose membranes (Bio-Rad, Hercules, Calif., USA) using the Bio-Rad Mini Trans-Blot Apparatus as recommended by the manufacturer. The membranes were blocked by incubation with $1 \%(\mathrm{w} / \mathrm{v})$ bovine serum albumin in phosphate buffered saline containing $0.1 \%$ (v/v) Tween 20 (PBST) for $2 \mathrm{~h}$. After washing in PBST for $5 \mathrm{~min}$, the nitrocellulose was incubated overnight at $4{ }^{\circ} \mathrm{C}$ with the primary antibody diluted $1: 500$ (sheep anti-mouse MMP-9 IgG) (gift from Dr. G. Murphy) in phosphate buffered saline containing $0.05 \%$ Tween 20 and 
$1 \%$ bovine serum albumin (PBSTB). Thereafter, the nitrocellulose strips were washed for $1 \mathrm{~h}$ in PBST and incubated in PBSTB containing the second antibody at a dilution of 1:2000 (anti-sheep IgG, peroxidase-linked Fab fragments from Boehringer (Mannheim, Germany) for $1 \mathrm{~h}$. The strips were then extensively washed in PBST and incubated in enhanced chemoluminescence Western blotting detection reagent (Amersham, Amersham, Bucks., UK) and exposed to Kodak X-OMAT AR film (Sigma, Aldrich Chemie GmbH, Deisenhofen, Germany).

I mmunohistochemistry. Renal tissue was fixed in $4 \%$ buffered formalin. Paraffin kidney sections $(2 \mu \mathrm{m})$ were dewaxed and incubated with the primary antibody to TIMP-1 (rabbit antibovine antiserum, diluted $1: 200$, which was a gift from Dr. Y.A.De Clerck, The Children's Hospital of Los Angeles, Calif., USA) for $16 \mathrm{~h}$ at $4^{\circ} \mathrm{C}$.

Mouse anti-rabbit immunoglobulin $(1: 125)$ and a rabbit anti-mouse antiserum $(1: 30)$ were used as linkers with incubation periods of $30 \mathrm{~min}$ each. Sections then were incubated with an APAAP immune complex for 30 min followed by incubation with filtered alkaline phosphatase substrate solution for $20 \mathrm{~min}$ at $25^{\circ} \mathrm{C}$ (staining TIMP-1 red). Sections were counterstained with haematoxylin (staining cell nuclei blue). Nonspecific antibody reactions were assessed by omitting the primary antibody.

N orthern blot analysis. For Northern blotting total RNA from glomerular preparations of three animals was pooled yielding three pools of RNA. From each pool one Northern blot analysis was performed for each parameter resulting in three Northern blots for every parameter analysed. RNA was extracted from the glomeruli using the acid guanidinium thiocyanate phenol chloroform extraction method [27] as we described previously [28]. Briefly, all probes were radiolabelled with $\left.{ }^{32} \mathrm{P}\right] \mathrm{dCTP}$ (Amersham) using the DECAprime DNA labelling kit (Ambion, Austin, Tex. USA). Hybridization was carried out overnight at $42^{\circ} \mathrm{C}$. The filters were exposed to Kodak XOMAT AR film at $-80^{\circ} \mathrm{C}$ for $1-4$ days using intensifying screens (Appligene-Oncor, Heidelberg, Germany). After autoradiography, the filters were stripped and hybridized with a human glyceraldehyde 3-phosphate dehydrogenase (GAP$\mathrm{DH})$ cDNA probe (1.2 kb insert in the $\mathrm{pBR} 322$ vector). The autoradiographs were digitized using an EPSON GT 6000 scanner (Epson, Tokyo, Japan). For all RNA samples the density of each individual RNA band was normalized for that of a GAPDH mRNA band to correct for the difference in RNA loading and/or transfer. The densitometric values are mean$\mathrm{s} \pm \mathrm{SEM}$ from three Northern blots.

Plasmids containing cDNA for mouse MMP-2, MMP-9 were kindly provided by Dr. K. Tryggvason (University of Oulu, Finland) and cDNA for mouse TIMP-2 was a kind gift from Dr. K. Leco (University of Calgary, Canada). The mouse $\alpha_{1}$ IV collagen cDNA probe was obtained from ATCC \# 63020 (Rockville, Md., USA).

Rat TIMP-1 cDNA probe. The cDNA probe for rat TIMP-1 was obtained by using RT-PCR. Total RNA was extracted from cultured rat skin fibroblasts (ATCC \# CRL 1213). The RT reaction was carried out using Super Script II reverse transcriptase (Gibco, Eggenstein, Germany). Sense (5'-TTTGCA-TCT-CTG-GCC-TCT-G-3') and anti-sense (5'-AATGAC-TGT-CAC-TCT-CCA-G-3') primers were designed from rat TIMP-1 (GenBank/EMBL accession No U 06179). This primer pair was chosen to yield an expected product of 493 base pairs. The PCR product was subsequently cloned into a pCR 2.1 vector using the TA cloning kit (Invitrogen, NV Leek, The Netherlands) and verified by sequencing.
Table 1. Body and kidney weights, serum chemistry and albuminuria in obese Zucker rats and lean littermates

\begin{tabular}{lcc}
\hline & Obese & Lean \\
\hline Body weight $(\mathrm{g})$ & $607 \pm 19^{\mathrm{a}}$ & $399 \pm 21$ \\
Kidney weight $(\mathrm{g})$ & $1.40 \pm 0.27$ & $1.28 \pm 0.35$ \\
Glucose $(\mathrm{mmol} / \mathrm{l})$ & $11.4 \pm 0.6^{\mathrm{a}}$ & $8.8 \pm 0.3$ \\
Cholesterol $(\mathrm{mmol} / \mathrm{l})$ & $3.8 \pm 0.2^{\mathrm{a}}$ & $2.3 \pm 0.1$ \\
Triglycerides $(\mathrm{mmol} / \mathrm{l})$ & $4.3 \pm 0.4^{\mathrm{a}}$ & $0.8 \pm 0.1$ \\
Creatinine $(\mu \mathrm{mol} / \mathrm{l})$ & $46.9 \pm 0.9^{\mathrm{a}}$ & $43.3 \pm 0.9$ \\
Creatinine clearance $\left(\mu \mathrm{l} \times \mathrm{min}^{-1}\right)$ & $1548 \pm 135$ & $1815 \pm 82$ \\
Albuminuria $(\mathrm{mg} / 24 \mathrm{~h})$ & $33.9 \pm 8.1^{\mathrm{a}}$ & $2.70 \pm 0.24$
\end{tabular}

Data are given as means \pm SEM from nine animals in each group.

a $p<0.05$ for obese Zucker rats vs lean littermates

A nalytical methods. Glomerular hydroxyproline content was determined by the chloramine $\mathrm{T}$ method modified according to Bergman et al. [29]. Total collagen in the glomerular homogenate was calculated on the assumption that collagen contains $12.7 \%$ of hydroxyproline by weight. Final results were expressed as $\mu \mathrm{g}$ of collagen per 1000 glomeruli.

Albuminuria was quantitated by nephelometry (Behring Nephelometer 100; Behring Werke, Marburg, Germany) according to Boege et al. [30] using rabbit anti-rat albumin antibodies (Organon Technika, Eppelheim, Germany).

Analysis of serum samples for glucose and lipids was performed using a Technicon autoanalyser (Bayer Diagnostics, Munich, Germany).

Statistical analysis. Results are expressed as means \pm SEM. Statistical analysis was performed using the unpaired Student's t-test. Significance was accepted at the $5 \%$ level.

\section{Results}

Clinical parameters. The phenotypic characterization of 24-week-old obese Zucker rats and their lean, age-matched littermates (control animals) are summarized in Table 1. Obese Zucker rats displayed an increment in body weight $(+52 \%)$ and a slight, but not significant, increase in kidney weight. Obese rats became slightly hyperglycaemic and developed hyperlipidaemia with an 1.7-fold rise in cholesterol and a 5.2-fold increase in triglycerides as compared to lean control animals. The difference in serum creatinine values was just reaching significance, while creatinine clearance was unchanged. As a sign of an altered glomerular barrier function, there was substantial albuminuria in the obese animals by week 24 (Table 1).

Renal histomorphology. As can be seen in Figure 1 obese Zucker rats displayed considerable matrix accumulation within the mesangium, while the number of mesangial cells was normal. Some endothelial cells appeared vacuolated. Capillary walls were thickened even in preserved glomerular tufts. Nodular mesangial lesions were not encountered. 


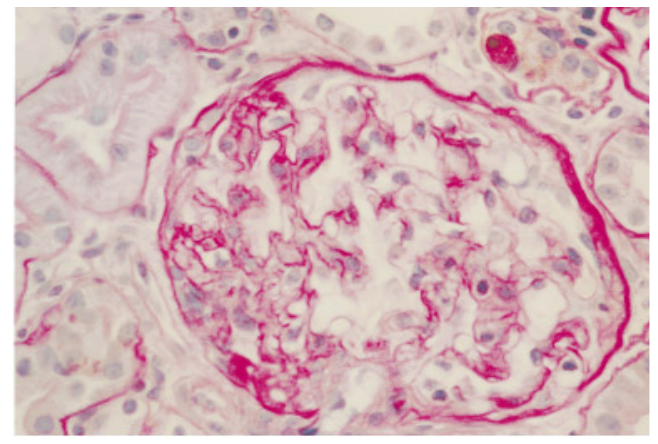

A

Obese

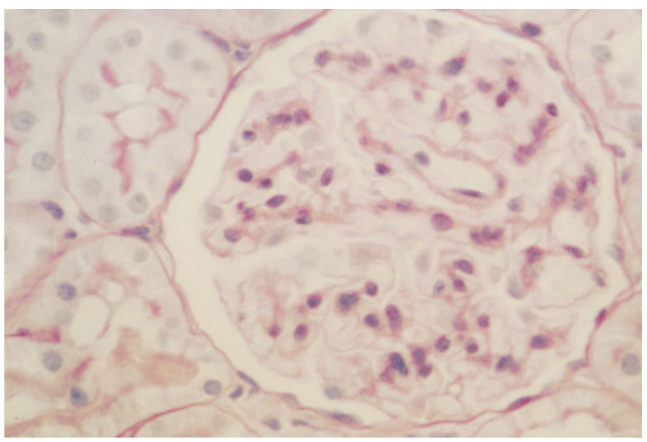

B
Lean
Fig. 1. (A , B ) Light microscopy of glomeruli from (A ) 24week-old obese Zucker rats and (B) their lean, age-matched littermates. (Periodic acid Schiff stain, $\times 500$ )

G lomerular collagen content. Total collagen content was significantly higher in glomeruli from obese $\mathrm{Zu}$ cker rats (Obese: $4.1 \pm 0.5$ vs controls: $2.5 \pm 0.26 \mu \mathrm{g}$ collagen $/ 10^{3}$ glomeruli; $\left.n=9, p<0.05\right)$. The number of isolated glomeruli per kidney was comparable in both groups (Obese: $23.495 \pm 1745$ vs Controls: $24.135 \pm 1532$ glomeruli/kidney, $n=9$ ) (Fig. $2 \mathrm{~A})$.

G lomerular gelatinolytic activities. Gelatinolytic activity in isolated glomeruli from obese Zucker rats was significantly lower compared to lean littermates (Obese: $431 \pm 52$ vs controls: $653 \pm 56 \mathrm{mU} / 10^{3}$ glomeruli; $\mathrm{n}=9 ; \mathrm{p}<0.05$ ) (Fig. 2B). These measurements were performed in the presence of the serine proteinase inhibitor PMSF (4 mmol/l). The gelatinolytic activities found in glomeruli from control and obese animals were mainly due to latent forms of MMPs, since measurements without prior activation by oxidized glutathione gave activities of less than $10 \%$ of total gelatinolytic activity. Addition of EDTA resulted in a more than $95 \%$ inhibition, indicating that these activities were in fact due to MMPs (data not shown).

Fig. 2. (A , B ) Total collagen content (A) and gelatinolytic activities (B) in glomeruli from obese Zucker rats and their lean littermates. $(n=9, p<0.05)$

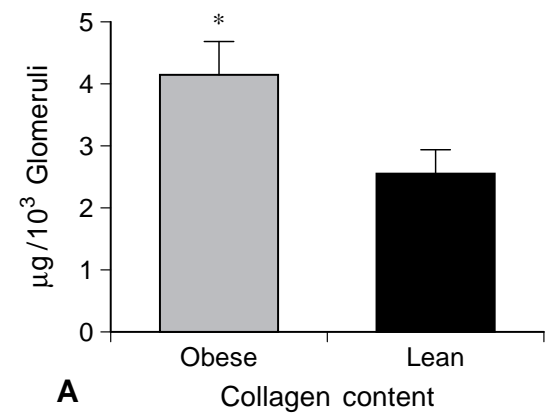

To further define these gelatinolytic activities, samples were subjected to gelatin zymography. Bands of activity were identified at 72, 68 and $62 \mathrm{kDa}$ from both obese and control animals (Fig. 3, lanes A and B). This finding suggests that the activity was due to gelatinase A (MMP-2). The intensity of gelatinase A bands was not different between glomeruli from obese or control rats. Moreover, glomeruli from lean littermates also displayed two bands of activity at 95 and $88 \mathrm{kDa}$ (Fig. 3, lane B) suggesting that these activities were due to gelatinase B (MMP-9). By contrast, MMP-9 activity was primarily not detectable in glomeruli from obese rats (Fig. 3, lane A), when equal amounts of glomeruli from both obese and lean animals were subjected to electrophoresis. However, semipurification over a gelatin-sepharose column of a six-fold higher amount of glomeruli (as compared to lane A and B) allowed us to demonstrate minute amounts of MMP-9 activity in glomeruli from obese Zucker rats (Fig. 3, lane C), while in terms of MMP-2 this procedure resulted in gross over-loading of the gel.

Western blotting of glomerular M M P -9. Western blot analysis, using a polyclonal antibody to murine MMP-9, was performed to further characterize these glomerular enzyme activities. This antiserum recognized a protein band of $88 \mathrm{kDa}$ in glomeruli from control animals (Fig. 3, lane E), which exactly corresponded to the activity band identified by zymography. By contrast, MMP-9 protein was not detectable in glomeruli from obese Zucker rats (Fig.3, lane D).






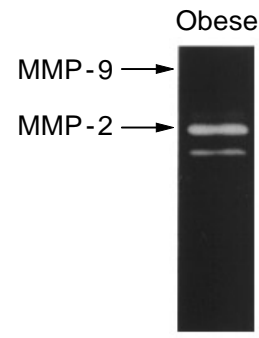

A

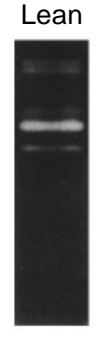

B

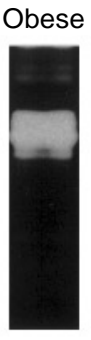

C

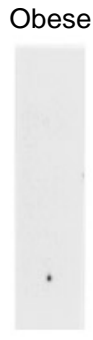

D

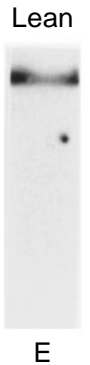

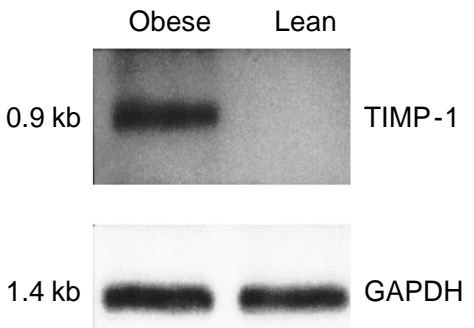

Fig. 3. Zymogram of MMP-2 and MMP-9 (lanes A, B and C) and Western blot analysis of MMP-9 (lanes D and E) in glomeruli from obese Zucker rats and their lean littermates. The intensity of MMP-2 bands (72, 68 and $62 \mathrm{kDa})$ was not different between glomeruli from obese and lean animals (lanes $\mathrm{A}$ and B). MMP-9 activity was not detectable in glomeruli from obese rats (lane A) when equal amounts of the glomerular preparation from both obese and lean animals were subjected to electrophoresis (lanes $\mathrm{A}$ and $\mathrm{B}$ ). Lane $\mathrm{C}$ demonstrates the presence of minute amounts of MMP-9 (95 and $88 \mathrm{kDa}$ ) in glomeruli from obese rats when a six-fold concentrated preparation of glomeruli was loaded on the gel. The antiserum to MMP-9 a protein band of $88 \mathrm{kDa}$ in glomeruli from lean rats (lane $\mathrm{E}$ ), while MMP-9 protein was not detectable in glomeruli from obese animals (lane D)
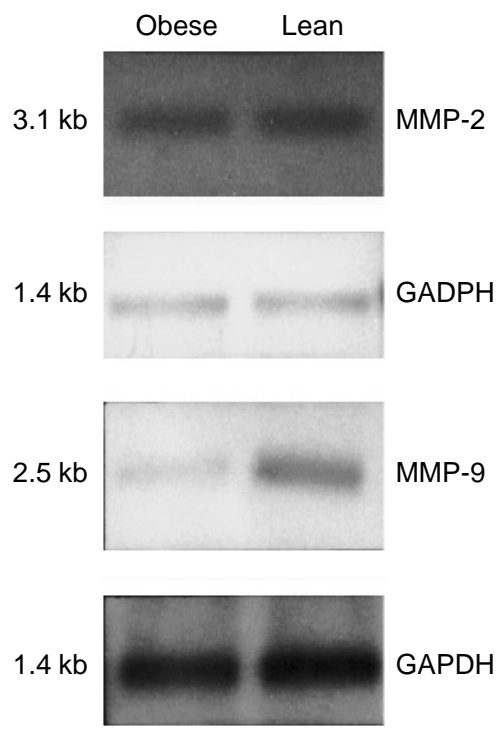

Fig. 4. Northern blot hybridization of glomerular MMP-2 and MMP-9 mRNA of obese Zucker rats and their lean littermates. There was no difference in the expression of mRNA specific for MMP-2 between glomeruli from obese and lean animals. Levels of mRNA coding for MMP-9 were $4.6 \pm 0$.6-fold lower $(\mathrm{n}=3 ; \mathrm{p}<0.05)$ in glomeruli from obese as compared to lean animals. Expression of GAPDH mRNA in the same membrane is shown on the lower panel

Glomerular mRNA expression of MMP-2 and MMP-9. In agreement with the zymography mRNA expression of MMP-2 revealed no difference between glomeruli from obese and control animals (obese: $1.1 \pm 0.5$ vs, lean: $1.0 \pm 0.3$ ). On the other hand, mRNA of MMP-9 was significantly decreased in glomeruli isolated from obese rats as

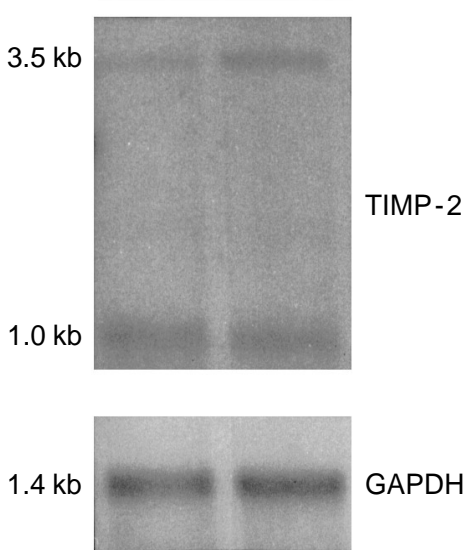

Fig. 5. Northern blot hybridizations $(n=3)$ of glomerular TIMP-1 and TIMP-2 mRNAs of obese Zucker rats and their lean littermates. Glomeruli from obese rats revealed a clearly visible band of TIMP-1 mRNA, while TIMP-1 mRNA was not detectable in glomeruli from lean controls. As measured by densitometry, the levels of mRNA coding for TIMP-2 were identical in obese and lean animals (obese: $1.1 \pm 0.3$ vs lean: $1.0 \pm 0.4 ; n=3)$. Expression of GAPDH mRNA in the same membrane is shown on the lower panel

compared to controls (4.6 \pm 0.6 -fold, $n=3 ; p<0.05)$ (Fig.4).

G lomerular mR N A expression of TIM P-1 and TI M P2. In order to address the potential role of the specific tissue inhibitors of metalloproteinases (TIMPs) in the reduction of glomerular gelatinolytic activity in the obese Zucker rat, Northern blot analysis of TIMP-1 and TIMP-2 mRNAs was performed (Fig. 5). TIMP1 mRNA was not detected in glomeruli from control animals with this technique, but could be demonstrated after amplification with RT-PCR (data not shown). On the other hand, glomeruli from obese rats revealed a clearly visible band of TIMP-1 mRNA in the Northern blots $(n=3)$, suggesting that mRNA of TIMP-1 was up-regulated. In terms of TIMP-2, there was no difference in glomerular mRNA between obese and lean control animals, when evaluated by densitometry (obese: $1.1 \pm 0.3$ vs lean: $1.0 \pm 0.4 ; n=3$ ).

Reverse zymography. TIMPs were identified using zymography (by their ability to inhibit gelatinase activity) as more intensely stained bands at $29 \mathrm{kDa}$ in glomeruli from both obese and control animals. 


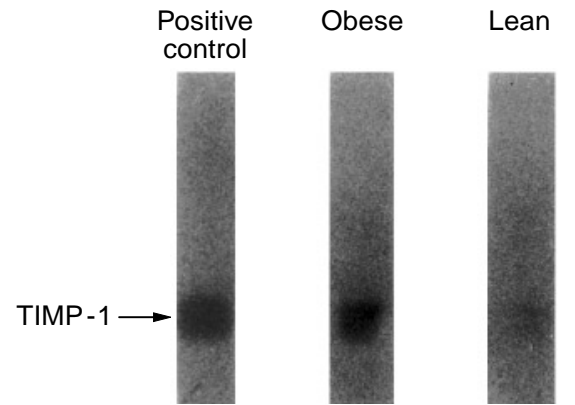

Fig. 6. Reverse zymography of TIMP-1 activity in glomeruli from obese Zucker rats and their lean littermates. Glomeruli from obese animals displayed more intense bands of TIMP-1 activity than those from lean rats

These bands were corresponding well to those observed with the positive control for TIMP-1 and to the reported molecular weight of this inhibitor. In terms of intensity, glomeruli from obese rats displayed a more intense band of TIMP-1 than glomeruli from lean control animals, suggesting that TIMP-1 activity was enhanced in glomeruli from obese animals. TIMP-2 activity was not detectable by reverse zymography (Fig. 6).

TIMP-1 immunohistochemistry. As can be seen in Figure 7, TIMP-1 was weakly expressed in glomeruli from lean control animals. Only a few endothelial cells showed positive reactions by the specific antibody. By contrast, glomeruli from obese animals displayed considerably stronger expression of TIMP-1. TIMP-1 staining appeared mostly within endothelial cells which were frequently swollen and transformed into foam cells. Non-specific antibody reaction was not observed when the antibody to TIMP-1 was ommitted from the protocol (data not shown).

Fig. 7. (A , B ) Immunohistochemical staining of TIMP-1 in glomeruli from $(\mathbf{A})$ obese Zucker rats and (B) their lean littermates (APAAP, $\times 500)$. In comparison to lean controls, glomeruli from obese animals displayed considerably stronger expression of TIMP-1 $\alpha_{1}$ IV collagen chain mRNA. Northern blots of mRNA for the $\alpha_{1}$ IV collagen chain in glomeruli from obese Zucker rats and lean control animals are shown in Figure 8. Densitometric evaluation of the respective bands normalized by mRNA for GAPDH demonstrated a $2.1 \pm 0.8$-fold $(n=3 ; p<0.05)$ increment in glomerular mRNA for the $\alpha_{1}$ IV collagen chain in obese as compared to control animals.

\section{Discussion}

Our findings provide evidence for a reduction of glomerular gelatinolytic activity in obese Zucker rats at an early state of glomerulosclerosis. This appears to be due to decreased MMP-9 synthesis, since the expression of MMP-9 mRNA was down-regulated in glomeruli from obese animals. MMP-9 specific protein was no longer detectable by Western blotting, but MMP-9 activity was still visible in gelatin zymograms. By contrast, glomeruli from lean control rats contained MMP-9, which could be detected by both Western blotting and gelatin zymography. In addition, there was upregulation of TIMP- 1 mRNA as well as TIMP-1 specific protein in glomeruli from obese animals. In comparison with lean control rats, there was no change in glomerular MMP-2 in terms of activity and mRNA expression in obese animals. TIMP-2 mRNA levels were identical in both groups of rats. This reduction in glomerular gelatinolytic activity was paralleled by an increment in collagen synthesis as evidenced by enhanced expression of mRNA for the $\alpha_{1}$ IV collagen chain. Both processes resulted in glomerular matrix accumulation which was readily apparent by light microscopy as well as enhanced total glomerular collagen content.

These observations of reduced gelatinolytic activity in isolated glomeruli from obese Zucker rats are in agreement with earlier reports which have shown in this model reduced neutral proteolytic actitivity against azocasein as a substrate in isolated glomeruli $[7,22]$. In terms of individual metalloproteinases the presence of MMP-2 and MMP-9 within glomeruli $[11,31]$ as well as in cultured glomerular mesangial [12] and epithelial cells [32] is well documented.

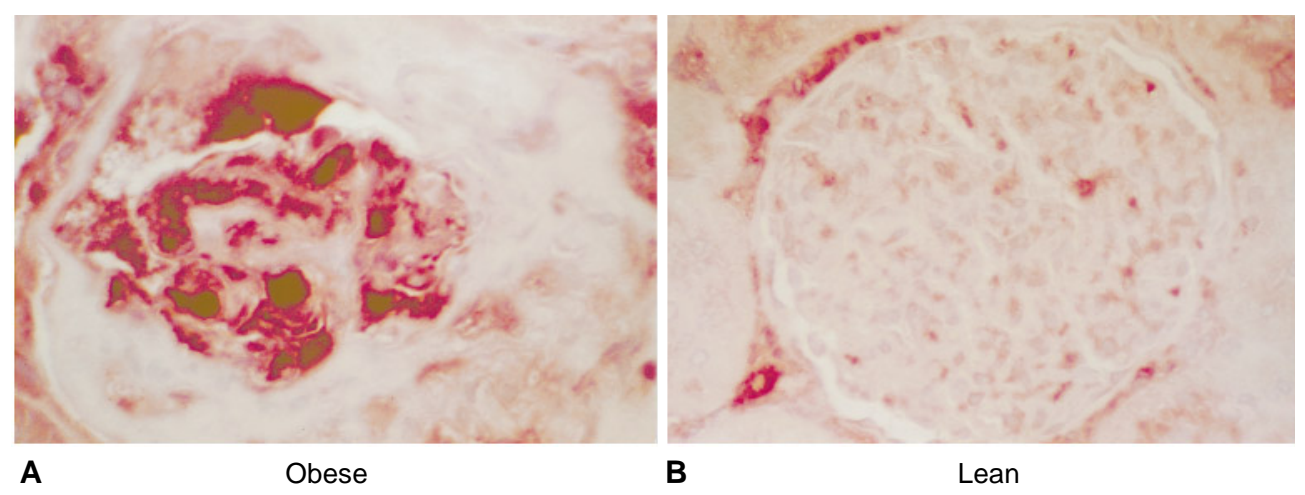




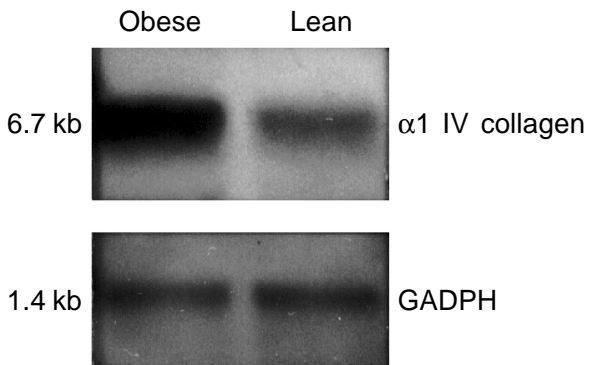

Fig. 8. Northern blot hybridization of glomerular mRNA coding for the $\alpha_{1}$ IV collagen chain from obese Zucker rats and lean littermates. The mRNA levels for the $\alpha_{1}$ IV collagen chain, measured by densitometry, were $2.1 \pm 0.8$-fold higher in obese animals $(n=3 ; p<0.05)$ as compared to lean controls. Expression of GAPDH mRNA in the same membrane is shown on the lower panel

Our finding of decreased glomerular MMP-9 may be critical for the evolution of glomerulosclerosis, since Jacot and co-workers [33] have reported that MMP-9, both in terms of mRNA and the secreted protein, is absent in cultured mesangial cells obtained from severely sclerotic glomeruli from mice transgenic for bovine growth hormone. Based on these findings the authors postulated that the lack of MMP-9 was the cause of the glomerular sclerosis. In our experiments there was not complete absence of MMP9 , since specific mRNA and enzyme activity were reduced, but still demonstrable in the obese animals.

In contrast to MMP-9, MMP-2 in terms of mRNA expression and activity (zymography) remained unchanged in glomeruli from obese animals. This discordant behaviour may be explained by the fact that MMP-2 and MMP-9 are independently regulated. Analysis of the MMP-2 gene promotor region has revealed striking differences with the MMP-9 promotor. Most notably, there is an absence of both a TATA box and a TRE sequence, which may explain the absent response of MMP-2 to TPA [34]. The absence of a TATA box and the presence of multiple SP-1 sites are typical features of a housekeeping gene [35], In fact, constitutive expression of MMP-2 has been observed in fibroblasts. In keeping with the presence or absence of these regulatory elements, in a number of cell lines MMP-2 secretion is not influenced by TPA, tumour necrosis factor (TNF)- $\alpha$, TNF- $\beta$ or interleukin- 1 , agents that do stimulate the expression of MMP-9 [36].

A second level of control of MMP activities is achieved through specific inhibitors (TIMPs) of which two, TIMP-1 and TIMP-2, were investigated in the present study. These two inhibitors were addressed, as it has been shown previously that both TIMP-1 and TIMP-2 are expressed in glomeruli of various species [31, 37] as well as cultured mesangial and epithelial cells [12, 32]. In our experiments TIMP-1 was just detectable in glomeruli from lean control rats in terms of both activity (by reverse zymography) and protein (by immunohistochemistry). Our inability to show mRNA for TIMP-1 in glomeruli from lean animals was due to limitations in the sensitivity of Northern blot hybridization, because the specific mRNA could be detected by RTPCR (data not shown), indicating that low level expression of TIMP-1 mRNA does occur in the normal rat glomerulus. The observation of increased expressions of TIMP-1 mRNA and specific protein in glomeruli from obese Zucker rats is in agreement with Lavaud et al. [38] who found enhanced levels of mRNA for both TIMP-1 and TIMP-2 in microdissected glomeruli from the same strain of animals using RT-PCR.

Up to now only a small number of investigators have addressed the relationship between the regulation of MMPs and the evolution of glomerulosclerosis. Jones et al. [39] demonstrated increased TIMP-1 mRNA in the kidney of aminonucleoside-treated rats. In this model the appearance of TIMP-1 protein within glomeruli correlated with the development of sclerosis, while mRNAs for MMP-1 and MMP-3 in the renal cortex remained unchanged. Similar findings have been reported by Nakamura et al. [40] in the same model of glomerulosclerosis. These authors also observed increased mRNA levels for TIMP-1 in parallel to the development of glomerulosclerosis. They also found MMP-2 mRNA expression to be enhanced, while mRNA specific for MMP-9 could not be detected by Northern blotting [40]. In humans Carome et al. [37] described increased gene expression for TIMP-1 and TIMP-2 in glomeruli derived from patients with diffuse glomerulosclerosis as compared to glomeruli from normal kidneys. The same authors [31] also found the glomerular expression of MMP-2 mRNA to be increased in mice transgenic for bovine growth hormone, while TIMP-1 gene expression could not be detected in these murine glomeruli.

In terms of the obese Zucker rat the potential mechanisms leading to alterations in glomerular MMP-9 and TIMP-1 are unknown. However, some authors have postulated that hyperlipidaemia is an important factor in the evolution of glomerulosclerosis [41-43]. Thus, Kim et al. [44] showed that low-density lipoproteins (LDL) do stimulate in a dose-dependent manner the expression of mRNAs for the $\alpha_{1}$ IV collagen chain as well as TIMP-2 in cultured rat mesangial cells. No significant effect of LDL on MMP-2 gene expression was found. Guijarro et al. [45] were able to induce mesangial matrix expansion in cholesterol-fed rats based on an increase in type IV collagen, fibronectin and laminin (shown by immunohistochemistry). In parallel, mRNA expressior for the $\alpha_{1}$ IV collagen chain and for TIMP-2 (TIMP1 mRNA was not studied) were enhanced, suggesting that hyperlipidaemia does influence both matrix synthesis as well as degradation. More recently, using uninephrectomized rats with dietary-induced 
hypercholesterolaemia Eddy et al. [46] reported on tubulointerstitial matrix expansion with increased synthesis of matrix components as well as upregulation of TIMP-1.

The pathogenetic relationship between hyperlipidaemia and glomerular injury remains unclear, although certain morphologic parallels with atherosclerosis suggest that oxidized LDL and monocyte/macrophages may play an important role [47]. Hyperlipidaemia in the obese Zucker rat is in fact associated with an early influx of macrophages into the glomerulus [38], and as these cells are capable to produce a number of cytokines and growth factors, it is conceivable that monocyte/macrophage infiltration is important in initiating and maintaining glomerular injury [48]. Among these cytokines TGF- $\beta 1$ has been considered to be particularly critical for glomerular matrix expansion and sclerosis [49]. In the present study, TGF- $\beta 1$ specific mRNA levels were unchanged in glomeruli from the obese Zucker rat (data not shown) as compared to lean littermates. This observation questions the role TGF- $\beta 1$ in this specific model of glomerulosclerosis. However, as we have no data on the latent and active forms of this growth factor a final conclusion on the impact of TGF- $\beta$ cannot be drawn at present.

Taken together, the work presented here is the first to show that net gelatinolytic activity of the whole glomerulus is reduced already at the onset of sclerosis in the obese Zucker rat, and that this reduction is based on decreased gene expression of MMP9 leading to a reduced content of MMP-9 within the glomerular matrix. In addition, over-expression of the metalloproteinase inhibitor TIMP-1 in the glomerulus will have further intensified the suppression of matrix degradation in this model.

A cknowledgements. This work was supported by the Deutsche Forschungsgemeinschaft and the Liese-Meitner-Programm. We thank Dr. G. Murphy for providing us with antibodies to mouse MMP-9, a preparation of active rabbit skin gelatinase and purified human TIMP-1. We are also grateful to Dr. $\mathrm{K}$. Tryggvason for cDNAs of MMP-2 and MMP-9 as well as to Dr. K. Leco for the TIMP-2 cDNA and to Dr. Y.A. DeClerck for the antibodies to TIMP-1.

\section{References}

1. Zucker LM (1965) Hereditary obesity in the rat associated with hyperlipidemia. Ann NY Acad Sci 131: 447-458

2. Ionescu E, Sauter JF, Jeanrenaud B (1985) Abnormal oral glucose tolerance in genetically obese (fa/fa) rats. Am J Physiol 248: E500-E506

3. Kasiske BL, O'Donnell MP, Keane WF (1990) The obese Zucker rat model of glomerular injury in type II diabetes. J Diabetic Complications 1: 26-29

4. Kasiske BL, Cleary MP, O'Donnell MP, Keane WF (1985) Effects of genetic obesity on renal structure and function in the Zucker rat. J Lab Clin Med 106: 598-604

5. O'Donnell MP, Kasiske B, Cleary MP, Keane WF (1985) Effects of genetic obesity on renal structure and function in the Zucker rat. II. Micropuncture studies. J Lab Clin Med 106: 605-610

6. Keane WF, Mulcahy WS, Kasiske BL, Kim Y, O'Donnell MP (1991) Hyperlipidemia and progressive renal disease. Kidney Int 39 [Suppl 31]: S41-S48

7. Paczek L, Teschner M, Schaefer RM, Heidland A (1991) Intra-glomerular fibronectin accumulation and degradation in obese Zucker rats. Diabetologia 34: 786-789

8. Fioretto P, Keane WF, Kasiske BL, O'Donnell MP, Klein DJ (1993) Alterations in glomerular proteoglycan metabolism in experimental non-insulin dependent diabetes mellitus. J Am Soc Nephrol 3: 1694-1704

9. Lovett DH, Sterzel RB, Kashgarian M, Ryan JL (1983) Neutral proteinase activity produced in vitro by cells of the glomerular mesangium. Kidney Int 23: 342-349

10. Davies M, Thomas GJ, Martin J, Lovett DH (1988) The purification and characterization of a glomerular-basementdegrading neutral proteinase from rat mesangial cells. Biochem J 251: 419-425

11. Lovett DH, Johnson RG, Marti HP, Martin J, Davies M, Couser EG (1992) Structural characterization of the mesangial cell type-IV collagenase and enhanced expression in a model of immune complex-mediated glomerulonephritis. Am J Pathol 141: 85-98

12. Martin J, Knowlden J, Davies M, Williams JD (1994) Identification and independent regulation of human mesangial cell metalloproteinases. Kidney Int 46: 877-885

13. Davies M, Martin J, Thomas GJ, Lovett DH (1992) Proteinases and glomerular matrix turnover. Kidney Int 41: 671-678

14. Woessner JF (1991) Matrix metalloproteinases and their inhibitors in connective tissue remodelling. FASEB J 5: 2145-2154

15. Matrisian LM (1992) The matrix-degrading metalloproteinases. Bioassays 14: 455-463

16. Docherty AJP, Murphy G (1990) The tissue metalloproteinase family and the inhibitor TIMP: a study using cDNAs and recombinant proteins. Ann Rheum Dis 49: 469-479

17. Cawston TE, Galloway WA, Mercer E, Murphy G, Reynolds JJ (1981) Purification of rabbit bone inhibitor of collagenase. Biochem J 195: 159-165

18. De Clerk YA, Yean TD, Ratkin BJ, Lu HS, Langley KE (1989) Purification and characterization of two related but distinct metalloproteinase inhibitors secreted by bovine endothelial cells. J Biol Chem 264: 17445-17453

19. Stetler-Stevenson WG, Brown PD, Onista M, Levy AT, Liotta LA (1990) Tissue inhibitor of metalloproteinase-2 (TIMP-2) mRNA expression in tumor cell lines and human tumor tissues. J Biol Chem 265: 13933-13938

20. Pavloff N, Staskus PW, Kishnani NS, Hawkes SP (1991) A new inhibitor of metalloproteinases from chicken: ChIMP-3. A third member of the TIMP family. J Biol Chem 267: 17321-17326

21. Greene J, Wang MS, Liu YL, Raymond LA, Rosen C, Shi YN (1996) Molecular cloning and characterization of human tissue inhibitor of metalloproteinase 4. J Biol Chem 271: 30375-30380

22. Teschner M, Paczek L, Schaefer RM, Heidland A (1991) Obese Zucker rat: potential role of intraglomerular proteolytic enzymes in the development of glomerulosclerosis. Res Exp Med 191: 129-135

23. Schaefer L, Schaefer RM, Heidland A (1994) Glomerular proteinase activities in streptozotocin-diabetic and obese Zucker rats. Kidney Int 47: 674 (Abstract)

24. Spiro RG (1984) Studies on the renal glomerular basement membrane. Preparation and chemical composition. J Biol Chem 242: 1915-1919 
25. Schaefer L, Schaefer RM, Ling H, Teschner M, Heidland A (1994) Renal proteinases and kidney hypertrophy in experimental diabetes. Diabetologia 37: 567-571

26. Laemmli UK (1970) Cleavage of structural proteins during the assembly of the head of bacteriophage T. Nature 227: 680-684

27. Chomczynski P, Sacchi N (1987) Single-step method of RNA isolation by acid guanidinium thiocyanate phenol chloroform extraction. Anal Biochem 162: 156-159

28. Schaefer L, Han X, Gretz N et al. (1996) Tubular gelatinase A (MMP-2) and its tissue inhibitors in polycystic kidney disease in the Han:SPRD rat. Kidney Int 49: 75-81

29. Bergman J, Loxley R (1963) Two improved and simplified methods for the spectrophotometric determination of hydroxy-proline. Anal Chem 53: 1963-1965

30. Boege F, Koehler B, Liebermann F (1990) Identification and quantification of Bence-Jones proteinuria by automated nephelometric screening. J Clin Chem Clin Biochem 28: $37-42$

31. Carome MA, Striker LJ, Peten EP et al. (1994) Assessment of 72-kd gelatinase and TIMP-1 gene expression in normal and sclerotic murine glomeruli. J Am Soc Nephrol 5: 1391-1399

32. Knowlden J, Martin J, Davies M, Williams JD (1995) Metalloproteinase generation by human glomerular epithelial cells. Kidney Int 47: 1682-1689

33. Jacot TA, Striker GE, Stetler-Stevenson MA, Striker LJ (1996) Decreased mesangial cell MMP-9 as a cause of sclerosis in mice transgenic for bovine growth hormone. J Am Soc Nephrol 7: 1756 (Abstract)

34. Sato H, Seiki M (1993) Regulatory mechanisms of $92 \mathrm{kDa}$ type IV collagenase gene expression which is associated with invasiveness of tumor cells. Oncogene 8: 395-405

35. Frisch SM, Morisaki JH (1990) Positive and negative transcriptional elements of the human type IV collagenase gene. Mol Cell Biol 10: 6524-6532

36. Unemori EN, Hibbs MS, Amento EP (1991) Constitutive expression of a $92 \mathrm{kDa}$ gelatinase by rheumatoid synovial fibroblasts and its induction in normal human fibroblasts by inflammatory cytokines. J Clin Invest 88: 1656-1662
37. Carome MA, Striker LJ, Peten EP et al. (1993) Human glomeruli express TIMP-1 mRNA and TIMP-2 protein and mRNA. Am J Physiol 264: F923-F929

38. Lavaud S, Michele O, Sassy-Prigent et al. (1996) Early influx of glomerular macrophages precedes glomerulosclerosis in the obese Zucker rat model. J Am Soc Nephrol 7: 2604-2615

39. Jones CL, Buch S, Post M, McCulloch L, Liu E, Eddy AA (1991) Pathogenesis of interstitial fibrosis in chronic purine aminonucleoside nephrosis. Kidney Int 40: 1020-1031

40. Nakamura T, Fukui M, Ebihara I, Tomino Y, Koide H (1994) Effects of low-protein diet on mRNA for ECM components, MMPs and TIMPs in glomeruli of focal glomerular sclerosis. Contrib Nephrol 107: 146-155

41. Kasiske BL, O’Donnell MP, Clearly MP, Keane WF (1988) Treatment of hyperlipidemia reduces glomerular injury in obese Zucker rats. Kidney Int 33: 667-672

42. Schloendorff D (1993) Cellular mechanisms of lipid injury in the glomerulus. Am J Kidney Dis 22: 72-82

43. Groene EF, Walli AK, Groene HJ, Miller B, Seidel D (1994) The role of lipids in nephrosclerosis and glomerulosclerosis. Atherosclerosis 107: 1-13

44. Kim SB, Kang SA, Cho YJ et al. (1994) Effects of low density lipoprotein on type IV collagen production by cultured rat mesangial cells. Nephron 67: 327-333

45. Guijarro C, Kasiske BL, Kim Y, O'Donnell MP, Lee HS, Keane EF (1995) Early glomerular changes in rats with dietary-induced hypercholesterolemia. Am J Kidney Dis 26: $152-161$

46. Eddy AA, Liu E, McCulloch L (1996) Interstitial inflammation and fibrosis in rats with diet-induced hypercholesterolemia. Kidney Int 50: 1139-1149

47. Qiunn MT, Parthasarathy S, Fong LG, Steinberg D (1987) Oxidatively modified low-density lipoproteins: a potential role in recruitment and retention of monocyte macrophages during atherogenesis. Proc Natl Acad Sci USA 84: 2995-2998

48. Schreiner GF (1991) The role of the macrophage in glomerular injury. Sem Nephrol 11: 268-275

49. Border WA, Noble NA (1993) Cytokines in kidney disease: The role of transforming growth factor-beta. Am J Kidney Dis 22: 105-113 